\title{
Comparisons of Tolerance of Ash Yellows Phytoplasmas in Fraxinus Species and Rootstock-Scion Combinations
}

\author{
W. A. Sinclair and H. M. Griffiths, Department of Plant Pathology, and T. H. Whitlow, Department of Floricul- \\ ture and Ornamental Horticulture, Cornell University, Ithaca, NY 14853
}

\begin{abstract}
Sinclair, W. A., Griffiths, H. M., and Whitlow, T. H. 1997. Comparisons of tolerance of ash yellows phytoplasmas in Fraxinus species and rootstock-scion combinations. Plant Dis. 81:395398.

Growth responses of different ash (Fraxinus) species and rootstock-scion combinations to ash yellows (AshY) phytoplasmas were compared in greenhouse experiments by expressing each measurement as a proportion of the final average value of the variable in noninoculated, ownrooted control trees. Phytoplasmal infection suppressed shoot growth of white ash (F. americana) and green ash (F. pennsylvanica) beginning when buds opened, but did not suppress velvet ash $(F$. velutina) until after 60 days of growth. AshY-associated growth losses in height, stem diameter, and root volume, averaged across two experiments, were 80, 93, and 98\%, respectively, in white ash; 60,57 , and $79 \%$ in green ash; and 23,0 , and $12 \%$ in velvet ash. Growth in height, but not in stem diameter or root volume, of diseased white ash on velvet ash rootstock was significantly greater than growth of diseased own-rooted white ash. White ash witches'-brooms grafted onto healthy velvet ash continued to grow but did not produce vigorous, dominant shoots. Growth of diseased velvet ash on white ash roots was severely suppressed in comparison with that of diseased own-rooted velvet ash. Management of AshY through the use of tolerant genotypes may require tolerance in both scions and rootstocks.
\end{abstract}

The phytoplasmal disease ash yellows (AshY) causes slow growth and premature decline of white ash (Fraxinus americana). It also suppresses growth or aggravates decline induced by other stressing agents in other ash species that have been studied $(13,14)$. Field observations and greenhouse experiments indicated that green ash $(F$. pennsylvanica) and velvet ash ( $F$. velutina) are more tolerant than white ash of phytoplasmal infection $(4-6,15,16)$.

In this paper, tolerance refers to the ability of a plant to grow while colonized by phytoplasmas. Tolerance can be quantified by comparing growth of diseased and healthy plants. Resistance refers to limitation of host colonization or suppression of phytoplasmal reproduction. Resistance has not been studied in Fraxinus. Both tolerance and resistance have been detected in Malus (8-10).

Rootstocks that tolerate or resist phytoplasmal infection can moderate symptom severity in susceptible scions of some plants. For example, pear decline was severe in susceptible cultivars on Pyrus pyrifolia or $P$. ussuriensis rootstocks, but symptoms were milder when resistant pear

Corresponding author: W. A. Sinclair

E-mail: was1@cornell.edu

Accepted for publication 16 January 1997.

Publication no. D-1997-0203-04R

(C) 1997 The American Phytopathological Society or quince rootstocks were used $(19,20)$. Phytoplasmal populations in Quince A rootstock infected with the pear decline agent slowly decreased to densities undetectable by fluorescence microscopy and nontransmissible by grafting (12). Commercial Malus rootstocks were less affected than many other Malus lines and genotypes challenged with the apple proliferation phytoplasma (8). Hybrids between $M$. sieboldii or $M$. sargentii and $M$. pumila, investigated as possible rootstocks, were resistant to this pathogen (9).

In the work presented here, we tested the hypothesis that AshY symptom severity is conditioned by the degree of tolerance of the rootstock. Objectives were to develop and implement a procedure for quantitative comparison of phytoplasmal tolerance of different ash taxa, and to compare the disease reactions of white ash and velvet ash on their own roots versus rootstocks of the opposite species.

\section{MATERIALS AND METHODS}

Plant materials and treatments. Dormant 1-year-old white ash seedlings from the Indiana Department of Natural Resources Nursery, Vallonia, were kindly provided by M. Coggeshall. Green ash were obtained as dormant 1-year-old seedlings from Lawyer's Nursery, Plains, MT. Velvet ash seedlings were grown from seed in a greenhouse. Hereinafter, we designate plant ages and the duration of experiments in terms of growth periods, because the duration and timing of growth and dor- mancy cycles of experimental plants did not coincide with natural growing seasons. All seedlings were planted in a fertilized mixture of equal volumes soil, sand, and peat moss in pots of 3-liter capacity for their second growth period and were transplanted into larger pots (18- or 35-liter capacity) for additional growth. During growth they were fertilized weekly by irrigation with dilute Peters EXCEL watersoluble fertilizer (15-5-15 N-P-K with micronutrients; Scott-Sierra Horticultural Products, Marysville, $\mathrm{OH}$ ) according to the manufacturer's recommendation. Growth periods lasted approximately 5 months, after which stems were cut off $30 \mathrm{~cm}$ or higher above the soil and leaves were removed from the residual stems. Cut tops were discarded. Trees were stored in their pots at 2 to $4^{\circ} \mathrm{C}$ in darkness for 4 months or longer during dormancy.

Experiments were performed in a screened greenhouse with natural light augmented by high-intensity-discharge sodium lamps to provide $16-\mathrm{h}$ photoperiods. Temperature ranges were 17 to $30^{\circ} \mathrm{C}$ during autumn-spring and 17 to $40^{\circ} \mathrm{C}$ during spring-summer. The arrangement of plants within experiments was random.

Inoculations were performed by grafting with diseased bark patches $($ c. $6 \times 25 \mathrm{~mm}$ ) or small leafy shoots. Control plants were grafted with their own bark (experiment 1) or were not grafted (experiments 2 to 4). Two AshY phytoplasma strains (populations propagated from single diseased plants) from central New York, maintained in potted velvet ash trees, were used interchangeably, one strain per experiment. Identity of the pathogen was verified by DNA-DNA hybridization with AshY-specific probes (3) and by immunofluorescence tests using an AshY-specific monoclonal antibody (7). Differences between the strains, if any, were not characterized. The presence of phytoplasmas in inoculum materials was verified by means of the DAPI (4',6-diamidino-2-phenylindole-2HCl) fluorescence test (11) before grafting. Infection of inoculated plants was assayed by the same test after 3 to 4 months of incubation. Plants in which phytoplasmas were not detected at first testing were retested during the next growth period.

Interspecific comparisons of AshY tolerance. Green, velvet, and white ash were compared in two experiments. For experiment 1 , diseased plants and controls in excess of the number planned for obser- 
vation were prepared during their second growth period by inoculating with bark patches containing phytoplasmas or, for the controls, by removing and replacing patches of their own bark. Infection was assayed by DAPI testing at the end of the growth period, 130 days after inoculation. Then the tops were cut off at $30 \mathrm{~cm}$ above the soil, and the trees were stored for dormancy. For the third growth period, nine diseased (DAPI-positive) plants and nine controls of each species were grown singly in pots containing 30 liters of soil mixture. Each plant was pruned to retain one main stem. Symptoms were recorded and growth measurements were made as described below.

In experiment 2, six plants per species were inoculated during their second growth period by top-grafting with single diseased shoots. Six plants per species were left as untreated controls. After 3 weeks, grafting was repeated on plants whose original scions appeared to be dying. After the growth period, tops (including scions) were cut off at $60 \mathrm{~cm}$ above the soil, and the trees were stored for dormancy. They were transplanted into pots containing 18 liters of soil mixture for the third growth period. After growth began, each plant was pruned to retain the single most vigorous shoot. DAPI tests were performed on in-

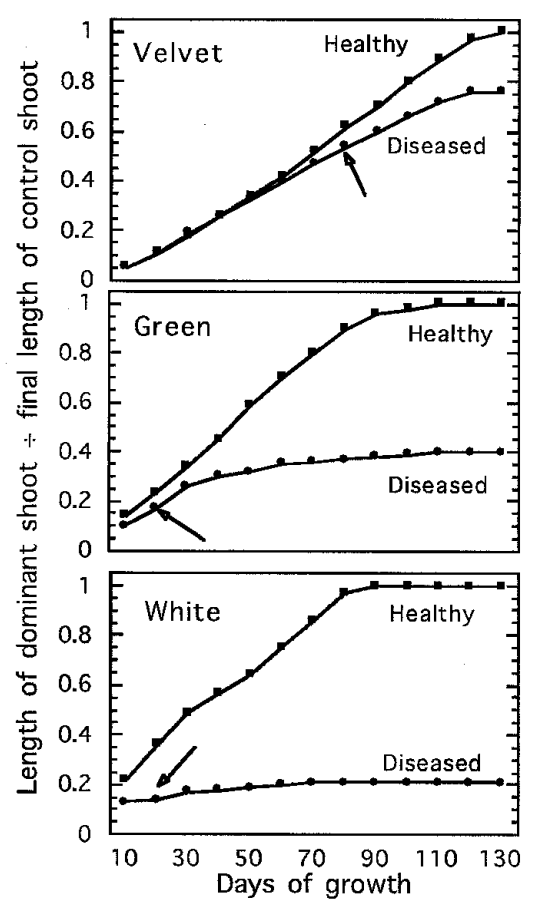

Fig. 1. Progress of apical growth of the dominant shoot of healthy and ash yellows-affected velvet ash, green ash, and white ash throughout one growth period. Shoot length is expressed as a proportion of the average final length of the longest dominant shoot on healthy plants. Each curve represents pooled data from 13 to 15 trees in two experiments. Arrows show when differences between healthy and diseased trees became significant at $P<0.05$. oculated plants at the end of the second growth period and were repeated during the third growth period for trees with negative initial results. Symptoms were recorded and growth measurements were made as described below.

Rootstock-scion interactions. Experiment 3 was a test of disease expression in white ash and velvet ash scions on rootstocks of the opposite species in comparison with disease expression in own-rooted plants of each species. Eight treatments, each with six replicate plants, were prepared as follows. Twelve healthy plants each of white ash and velvet ash were, at the beginning of their second growth period, grafted near the stem base with three buds from healthy plants of the other species. Twelve additional plants of each species remained ungrafted. After growth began, rootstock shoots on grafted plants were pinched off, and scions were thinned to one per plant. Eight weeks after grafting, six plants of each stock-scion combination and six own-rooted plants of each species were inoculated by top-grafting with diseased velvet ash shoots. The remaining plants were reserved as controls. After a further 4 months, the stems were cut off $60 \mathrm{~cm}$ above soil, and the trees were stored for dormancy. DAPI tests were performed on inoculated plants at the end of the second growth period and were repeated during the third growth period for those with negative initial results. Symptoms were recorded during the third growth period, and growth measurements were made at the end of the period as described below.

Experiment 4 was performed to learn whether phytoplasma-induced white ash witches'-brooms would undergo remission of the broom habit after grafting to healthy phytoplasma-tolerant rootstocks. Six growing velvet ash approximately $1.5 \mathrm{~m}$ tall were grafted near the $90-\mathrm{cm}$ level with single, small portions of leafy white ash witches'-brooms in which phytoplasmas were detected with the DAPI test. Each scion was c. $6 \mathrm{~cm}$ tall after trimming shoot tips and excess leaves. The inoculated trees and six noninoculated controls were allowed to complete the growth period. Then the tops were removed just above the level of the scions, and the trees were stored for dormancy. Early in the second growth period, each inoculated tree was pruned to retain one velvet ash shoot plus the white ash broom, while control trees were pruned to retain two shoots each. Trees were observed for 5 months; then the tops were again cut off just above the brooms, and the trees were stored for dormancy. As the third growth period began, the trees were again pruned to retain one velvet ash shoot plus the white ash broom or to retain two shoots on controls. Then, after 5 weeks, all velvet ash shoots were removed from three each of the trees with brooms and three controls. The remaining trees were not pruned. Final observations and measurements were made after 4 months.

Observations, measurements, and analyses. Growth periods were considered to begin when shoot tips became visible in the opening buds. The length of the dominant current-season shoot was measured at 10-day intervals during the third growth period in experiments 1 to 3 and at the end of each period in experiment 4 . Stem diameter $10 \mathrm{~cm}$ above the root collar was measured at the beginning and end of the third growth period in experiments 1, 2, and 3. Root health was assessed visually near the end of the second growth period ( 3 to 4 months after inoculation) in experiments 2 and 3 by temporarily removing plants from pots and examining roots that were visible at the exposed soil surface. At the end of these experiments, roots were washed, and those produced during the third growth period (outside the 3-liter pot space to which roots were restricted during the second period) were removed and their volume was measured as water displaced from a previously filled vessel. Foliar symptoms and other morphological abnormalities were noted but not quantified.

Analyses of data began with examinations for homogeneity of variance (17). When heterogeneity was detected, variance was stabilized and negative values were avoided by transforming data to $\log _{10}(1+$ value). Treatment effects within species or rootstock-scion combinations were evaluated by one-way ANOVA and linear contrasts of means (17). Then, in experiments 1 to 3 , comparisons of the impact of disease on growth of different ash species or scion-rootstock combinations were enabled by expressing each observed value of a measured variable as a proportion of the average final value of that variable in healthy, own-rooted plants of the same species. Data thus transformed are hereinafter termed standardized. Variance in standardized data was stabilized and negative values were avoided by transformation as described above. Treatment effects were evaluated by ANOVA, and means were compared by linear contrasts (17) or, in experiment 3, by least significant differences. Data from inoculated trees that remained healthy (DAPI-negative) were excluded from analyses.

\section{RESULTS}

Comparative responses of green, velvet, and white ash to infection. Similar means and patterns of variability in data for growth in height and stem diameter were obtained in experiments 1 and 2 . Therefore, data from the two experiments were pooled, resulting in 13 to 15 observations per treatment. Analyses of variance revealed highly significant $(P<0.001)$ effects of species and treatment, but no significant effect of experiment, on apical and radial growth. In green ash and white ash, apical growth rates of diseased plants 
diverged from those of healthy plants within the first 20 to 40 days after budbreak, while significant divergence was delayed until 60 to 100 (average 80) days in velvet ash (Fig. 1). The dominant shoot on the average diseased velvet ash after 130 days of growth was $77 \%$ as long as the corresponding shoot on healthy velvet ash. Corresponding means for green ash and white ash were 40 and $20 \%$, respectively (Fig. 1). All differences among these means were significant at $P<0.01$.

Significant $(P<0.01)$ suppression of radial growth occurred in diseased white ash and green ash in comparison with healthy controls and in comparison with diseased velvet ash (Fig. 2). Radial growth of diseased velvet ash was greater than that of healthy controls in each experiment, although the differences were not significant. This anomaly was associated with the production of more axillary shoots and thus more foliage on diseased than on healthy velvet ash during the last third of the growth period.

Root volume produced during the growth period following that in which trees were inoculated was measured in experiment 2 . In velvet ash, this volume was not significantly affected by AshY. Root growth of diseased green ash and white ash, however, was greatly suppressed in comparisons with controls and with other treatments (Fig. 2).

Disease-associated root necrosis varied among species. Dead rootlets were prominent on most inoculated white ash 3 to 4 months after grafting and appeared on the remaining inoculated white ash during the next growth period. Nearly all roots less than approximately $3 \mathrm{~mm}$ in diameter on diseased white ash died, and few or no new rootlets were produced during the third growth period. Severe disease-associated rootlet necrosis occurred on only two inoculated green ash, but root growth during the third growth period was greatly suppressed on all that became infected. Root necrosis was not observed on velvet ash or noninoculated control trees.

The severity of AshY-associated stem and leaf symptoms differed visibly between species, among trees within species, and among leaf positions on trees. Five inoculated white ash, but no plants of other species, died. The most severely affected white ash that remained alive had rosettes of light green or chlorotic, dwarfed, distorted leaves on tiny twigs at the tops of stems. Some white ash and green ash had unusually large leaflets or leaflets distorted by downward cupping, puckering, or abnormal outline. Diseased green ash produced axillary shoots near the stem apex toward the end of the growth period, giving the tops a bushy appearance. Occasional trees of all three species produced small witches'-brooms or dwarfed shoots with simple leaves near the soil line. Velvet ash, whether diseased or healthy, became more bushy than the other species, because buds in leaf axils produced shoots during the same growth period in which the buds formed. Three ranks of shoots formed within one growth period on diseased velvet ash, but only two ranks of shoots formed on healthy trees.

Rootstock-scion interactions on growth and AshY expression. Standards for growth comparisons in experiment 3 were healthy, own-rooted velvet ash and healthy, own-rooted white ash. Apical and radial growth of diseased velvet ash scions on white ash roots were severely suppressed in comparison with growth of diseased own-rooted velvet ash. This suppression was related to severity of root damage, as diseased white ash roots sustained severe necrosis before the third growth period and produced few new rootlets during that period, whether they were supporting white ash or velvet ash tops. Diseased white ash scions on velvet ash roots sustained significantly less growth suppression than did diseased ownrooted white ash. Velvet ash roots supporting diseased white ash tops remained alive but grew little (Fig. 3). Rootstockscion interactions on growth of healthy plants in experiment 3 were apparent as suppression of top and root growth of velvet ash on white ash roots and stimulation of top and root growth of white ash on velvet ash roots in comparison with ownrooted standards (Fig. 3). These differences lacked significance at $P=0.05$, however.

White ash witches'-brooms grafted on velvet ash rootstocks (experiment 4) all retained their initial form (dense cluster of stems) through two subsequent growth periods, even on trees that were pruned in the third growth period to permit shoot growth only in the brooms. The largest brooms produced shoots up to $20 \mathrm{~cm}$ long,

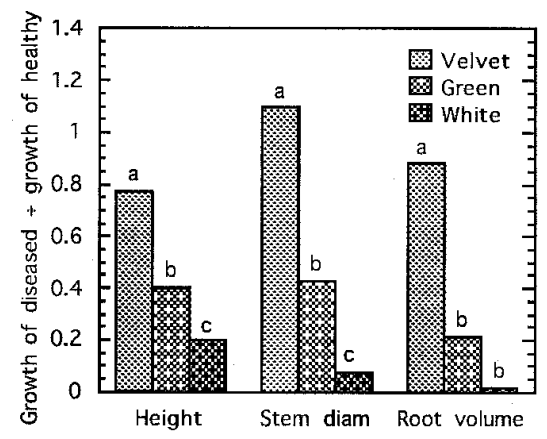

Fig. 2. Increase in height, stem diameter, and root volume of velvet, green, and white ash infected with ash yellows phytoplasmas during one growth period. Data are proportions of the corresponding mean values for healthy controls of the respective species. Height and diameter data are pooled from two experiments. Root data are from one experiment. For each variable, different letters above bars indicate significant $(P<0.05)$ differences among species means of log-transformed data as determined by linear contrasts. but the stems of these shoots were abnormally thin, and no shoot in a broom became dominant. Velvet ash shoots produced in each growth period from buds adjacent to the brooms displayed apical dominance and grew up to $150 \mathrm{~cm}$ (average $81 \mathrm{~cm}$ ), while the healthy control trees produced shoots up to $190 \mathrm{~cm}$ long (average $117 \mathrm{~cm}$ ).

\section{DISCUSSION}

The method described here for comparing phytoplasmal impact on growth of different ash species and scion-rootstock combinations can be utilized in other disease systems in which systemic infections retard plant growth. In a generalized version of the method, each measurement of a continuous variable would be expressed as a proportion of the average final value of that variable in healthy controls of the same plant type. Use of this scheme permits comparisons of growth curves and growth rates during particular time periods as well as comparisons of final size or yield. The method permitted repeatable

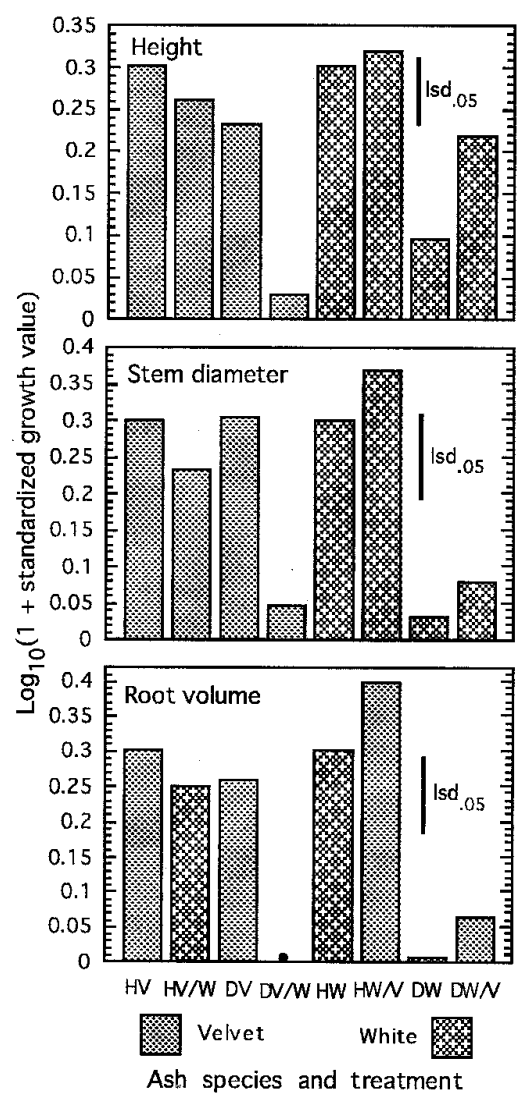

Fig. 3. Growth in height, stem diameter, and root volume of healthy and ash yellows-affected velvet ash and white ash on their own roots and on rootstocks of the other species. Standardized data (explanation in text) were transformed to $\log _{10}(1+$ value $)$ for analyses. Each bar represents the mean of six replicate trees. Treatment key: $\mathrm{H}=$ healthy, $\mathrm{D}=$ diseased, $\mathrm{V}=$ velvet ash, $\mathrm{W}=$ white ash, / = graft union. The symbol $\bullet$ denotes a value of zero. 
quantitative differentiation of three ash species with respect to phytoplasmal impact on growth. It will be useful for comparing cultivar reactions to AshY.

The quantitative comparisons in this study corroborate previous indications of differential tolerance of white ash, green ash, and velvet ash to infection by AshY phytoplasmas $(5,15,16)$. Tolerance in velvet ash was expressed as a delay in onset of height growth suppression. This delay, 80 days on average, was longer than the period required for completion of annual height growth under field conditions in the southwestern United States, where velvet ash is indigenous. Delayed suppression of height growth and the absence of radial growth suppression in diseased velvet ash in this study provide an explanation for previous failure to detect phytoplasmaassociated growth loss in this species in the field (15).

Phytoplasma-infected green ash and white ash, in contrast to velvet ash, displayed apical growth suppression beginning as soon as buds opened in the growth period following that of inoculation. Radial growth was also severely suppressed. These findings are consistent with field comparisons of diseased and healthy green ash and white ash in New York State (15).

Nonsignificantly greater radial growth of diseased than of healthy velvet ash was noted in each of three experiments. These differences were associated with prolonged growth of this species under greenhouse conditions at latitude $42^{\circ}$ north. Diseased velvet ash produced more shoots and foliage than healthy trees did near the end of the growth period, which may have increased the availability of carbon for wood production in stems.

We anticipated that diseased white ash scions on velvet ash rootstocks would grow more rapidly than diseased own-rooted white ash. Growth suppression in phytoplasma-infected velvet ash supported by white ash roots was also anticipated. These expectations were based on prior knowledge that rootlets of pot-grown phytoplasma-infected velvet ash remain alive, whereas comparable white ash rootlets die $(4,16)$. The outcome in white ash varied from that expected, however. Height growth, but not growth in stem diameter or root volume, of diseased white ash on velvet ash roots was significantly greater than that of diseased own-rooted white ash.

The greater suppression of diameter growth and root growth than of top growth in phytoplasma-infected white ash on velvet ash (Fig. 3) may reflect the sequential effects of depressed photosynthesis and allocation of a large proportion of fixed carbon to shoot growth. Greenhouse-grown green ash infected with virulent strains of the AshY phytoplasma had light-saturated photosynthetic rates only 20 to $30 \%$ as great as the rates in healthy control plants (T. H. Whitlow, unpublished). Diminished translocation of carbon from leaves toward roots of phytoplasma-infected elm and pear has been reported $(1,2)$.

Phytoplasma-resistant or tolerant rootstocks of some fruit trees have a suppressive influence on symptoms in scions (12,18-20). Unfortunately, white ash scions on phytoplasma-infected velvet ash rootstocks were not protected from severe growth suppression or death, and velvet ash scions on diseased white ash rootstocks became severely stunted. White ash witches'-brooms grafted to healthy velvet ash retained broom form, even when the only shoots allowed to grow were in the brooms. These rootstock-scion interactions probably represent a worst-case scenario for grafted ash trees colonized by AshY phytoplasmas, because the white ash seedlings used in the experiments represent the extreme of known AshY intolerance. Also, in our experience, AshY symptoms develop more rapidly and dramatically in potted trees in the greenhouse than they do in small trees inoculated in the field. These differences are associated with the training of pot-grown trees to 1 to 2 shoots growing from stumps each growth period and with storage temperatures milder than those of winter outdoors during dormancy. Even so, the findings indicate that management of AshY through the use of tolerant genotypes may require tolerance in both scions and rootstocks.

\section{ACKNOWLEDGMENTS}

This research was supported by the Horticultural Research Institute and the McIntire-Stennis Cooperative Forestry Program. We thank Ann Costigan, Alexander Larsen, and Pamela Mercure for help with plant maintenance, inoculations, and DAPI tests. J. D. Castello, G. W. Hudler, and anonymous reviewers provided helpful comments about the manuscript.

\section{LITERATURE CITED}

1. Braun, E. J., and Sinclair, W. A. 1978. Translocation in phloem necrosis-diseased American elm seedlings. Phytopathology 68:17331737.

2. Catlin, P. B., Olssen, E. A., and Beutel, J. A. 1975. Reduced translocation of carbon and nitrogen from leaves with symptoms of pear curl. J. Am. Soc. Hortic. Sci. 100:184-187.

3. Davis, R. E., Sinclair, W. A., Lee, I.-M., and Dally, E. L. 1992. Cloned DNA probes specific for detection of a mycoplasmalike organism associated with ash yellows. Mol. Plant-Microbe Interact. 5:163-169.

4. Dyer, A. T., and Sinclair, W. A. 1991. Root necrosis and histological changes in surviving roots of white ash infected with mycoplasmalike organisms. Plant Dis. 75:814-819.

5. Ferris, M. A., Castello, J. D., and Sinclair, W. A. 1989. Effects of virus and mycoplasmalike organism infection on green and white ash. Phytopathology 79:579-583.

6. Gleason, M. L., Parker, S. K., Engle, T. E., Flynn, P. H., Griffiths, H. M., Vitosh, M. A. and Iles, J. K. Ash yellows occurrence and association with slow growth of green ash in Iowa and Wisconsin cities. J. Arboric. In press.

7. Griffiths, H. M., Sinclair, W. A., Davis, R. E., Lee, I.-M., Dally, E. L., Guo, Y.-H., Chen, T. A., and Hibben, C. R. 1994. Characterization of mycoplasmalike organisms from Fraxinus, Syringa, and associated plants from geographically diverse sites. Phytopathology 84:119-126.

8. Kartte, S., and Seemüller, E. 1988. Variable response within the genus Malus to the apple proliferation disease. Z. Pflanzenkrankh. Pflanzenschutz 95:25-34.

9. Kartte, S., and Seemüller, E. 1991. Susceptibility of grafted Malus taxa and hybrids to apple proliferation disease. J. Phytopathol. 131:137-148.

10. Kartte, S., and Seemüller, E. 1991. Histopathology of apple proliferation in Malus taxa and hybrids of different susceptibility. J. Phytopathol. 131:149-160.

11. Seemüller, E. 1976. Investigations to demonstrate mycoplasmalike organisms in diseased plants by fluorescence microscopy. Acta Hortic. 67:109-112.

12. Seemüller, E., Schaper, U., and Kunze, L. 1986. Effect of pear decline on pear trees on 'Quince A' and Pyrus communis seedling rootstocks. Z. Pflanzenkrankh. Pflanzenschutz 93:44-50.

13. Sinclair, W. A., and Griffiths, H. M. 1994. Ash yellows and its relationship to dieback and decline of ash. Annu. Rev. Phytopathol. 32:49-60.

14. Sinclair, W. A., Griffiths, H. M., and Davis, R. E. 1996. Ash yellows and lilac witches'broom: Phytoplasmal diseases of concern in forestry and horticulture. Plant Dis. 80:468475.

15. Sinclair, W. A., Griffiths, H. M., and Treshow, M. 1993. Impact of ash yellows mycoplasmalike organisms on radial growth of naturally infected white, green, and velvet ash. Can. J. For. Res. 23:2467-2472.

16. Sinclair, W. A., Griffiths, H. M., and Treshow, M. 1994. Ash yellows in velvet ash in Zion National Park, Utah: High incidence but low impact. Plant Dis. 78:486-490.

17. Snedecor, G. W., and Cochran, W. G. 1989. Statistical Methods. 8th ed. Iowa State University, Ames.

18. Uyemoto, J. K., Kirkpatrick, B. C., and Cummins, J. N. 1991. Susceptibility of selected cherry clones and related species to Western X-disease. HortScience 26:15101511.

19. Westwood, M. N., Cameron, H. R., Lombard, P. B., and Cordy, C. B. 1971. Effects of trunk and rootstock on decline, growth and performance of pear. J. Am. Soc. Hortic. Sci. 96:147-150.

20. Westwood, M. N., and Lombard, P. B. 1983. Pear rootstocks: Present and future. Fruit Var. J. 37:24-28. 